\title{
ENSAIOS PARA UMA HISTÓRIA DO ATEÍSMO NO BRASIL
}

\author{
Essays for a history of atheism in Brazil
}

Diego Omar Silveira ${ }^{1}$

Como vários outros campos do conhecimento, os estudos da religião não avançam de modo uniforme, deixando lacunas que podem ser tomadas como indicadores tanto do interesse social por determinadas temáticas como das possibilidades conjunturais de desenvolver as pesquisas nas universidades e os debates públicos (na sociedade mais ampla) em torno de determinados assuntos. O caso do ateísmo no Brasil é bastante instigante.

Paula Montero e Eduardo Dullo (2014) já haviam demonstrado como "o silêncio em torno do ateísmo” (p. 59) em nosso país envolve vários aspectos, que vão desde uma insipiente produção sobre esse tema e da "ausência de personagens acadêmicos reconhecidos nesse debate” (p. 78) até o reforço à “percepção da sociedade brasileira como eminentemente religiosa” (p. 59), com a visibilização dos não-crente/ateus apenas em contendas públicas em torno da laicidade do Estado ou da defesa das minorias contra a discriminação (ou seja, questões ligadas, elas próprias, ao campo das crenças).

À baixa densidade numérica dos que se declaram ateus se somariam as dificuldades adicionais de alargar o debate sobre os sentidos da descrença para um “conjunto mais amplo das camadas cultas”, já que ele estaria “confinado ao pequeno círculo dos mais diretamente interessados pelo problema” (p. 77), bem como de construir um campo relativamente autônomo de intervenção (intelectual ou política) para esses sujeitos, por meio, por exemplo, de um ativismo organizado em grupos, associações ou mesmo comunidades virtuais.

Argumentos interessantes, mas que não contemplam, porém, mais detidamente e com a devida atenção, nem o avanço - paulatino, mas significativo - do percentual dos que se autodeclaram ateus/agnósticos nos últimos censos demográficos, nem a construção de identidades ateias e seus vínculos com o mercado editorial (que traduz cada vez mais os autores ateus contemporâneos, sobretudo os best-sellers) ou com o que é divulgado nas redes sociais.

\footnotetext{
${ }^{1}$ Graduado e Mestre em História na Universidade Federal de Ouro Preto (UFOP). Doutorando em Antropologia Social na Universidade Federal do Amazonas (UFAM). Professor do curso de História da Universidade da Universidade do Estado do Amazonas (UEA). É membro da Rede de Pesquisa: História e Catolicismo no mundo contemporâneo, do Centro de Estudos Políticos, Religião e Sociedade (CEPRES) e do Laboratório de Estudos Panamazônicos Práticas de Pesquisa e Intervenção Social (LEPAPIS). E-mail: diegomarhistoria@yahoo.com.br.
} 
Várias dessas questões são abordadas por Ricardo Oliveira da Silva no livro O ateísmo no Brasil: os sentidos da descrença nos séculos XX e XXI (Paco Editorial, 2020). Um trabalho que cumpre a difícil tarefa de ser uma obra se síntese - escrita com rigor acadêmico, mas com uma linguagem acessível também a um público leitor mais amplo - e a primeira abordagem mais sistemática sobre o tema no/para o Brasil. Segundo o autor, o texto é resultado da pesquisa intitulada Um mundo sem crença em Deus: um estudo sobre o ateísmo no anarquismo, comunismo e neoateísmo brasileiro e do oferecimento da disciplina sobre História do Ateísmo no curso de História da Universidade Federal do Mato Grosso do Sul (UFMS).

Dessa dupla incursão, no trabalho com bibliografia e fontes e na atuação no ensino superior, originaram-se os ensaios, mais ou menos autônomos, que compõem a obra e que, tomados em conjunto, oferecem um certo panorama - naturalmente incompleto - sobre os "sentidos da descrença” em diferentes momentos da vida nacional ao longo do novecentos e das primeiras décadas dos anos 2000. De modo geral, em todos os capítulos, uma dupla preocupação perpassa as análises do autor: em primeiro lugar, uma tentativa de fornecer ao leitor um panorama bibliográfico suficientemente amplo, de tal modo que tenhamos uma dimensão historiográfica dos assuntos; em segundo, um investimento na análise de algumas fontes (jornais, revistas, sites ateístas, estatuto das associações e entrevistas com lideranças), como exercício de análise histórica sobre como diferentes homens/mulheres ateus/ateias se articularam para expor publicamente seus pontos de vista, quase sempre em choque com o catolicismo hegemônico (e seus agentes institucionais) ou com um Estado imbricado, na maior parte do tempo, com as pautas religiosas.

O primeiro capítulo - Ateísmo e historiografia - apresenta uma ampla contextualização da proposta do livro, a começar pelas definições de sobre ateísmo, seja como "a descrença na existência de deuses” ou como “a crença de que Deus não existe” (p. 14). Vários autores, clássicos e contemporâneos, como Georges Minois, Julian Baginni, Michael Martin, Paul Cliteur e Stephen LeDrew (alguns ainda com suas obras sem tradução para o português) são mobilizados para esmiuçar essa categoria nos seus muitos vieses, dos mais abertos aos mais normativos. Cliteur, por exemplo, propõe que se pense o ateísmo como “uma escolha intelectual explícita do indivíduo, que opta após exame cuidadoso e consciente dos argumentos apresentados pelo teísta em favor da existência de Deus” (p. 15). Já LeDrew nos fornece “uma alternativa analiticamente mais produtiva” ao propor uma análise histórica sobre o que significa ser ateu (de raiz etimológica grega, atheos, onde a quer dizer 'sem’ ou ‘não' e theos quer dizer 'deus') em diferentes contextos sociais. Uma perspectiva que permite inclusive vislumbrar subcategorias, 
como “ateísmo científico” e “ateísmo humanista” (p. 16), para classificar as diferentes tradições intelectuais herdeiras da aposta iluminista no poder explicativo da razão e na superação das ideias e representações religiosas do mundo.

Além disso, Ricardo Silva também discute uma historiografia do ateísmo e o "relativo vazio historiográfico sobre o tema” (p. 20) no Brasil, em comparação com os estudos produzidos na filosofia, nas ciências sociais e nas ciências da religião. Alinhado à Minois, ele argumenta que esses poucos trabalhos refletem, ao mesmo tempo, a "conotação negativa que se atribui à descrença” e o fato de que "o ateísmo como fenômeno histórico com certa amplitude é recente em nosso país”. Daí as peculiaridades de nossa produção acadêmica sobre ateísmo: 1) "as pesquisas são recentes, com maior volume de trabalhos publicados nos primeiros anos do século XXI”; 2) elas estão mais concentradas na área das ciências da religião e as abordagens gravitam em torno dos estudos das crenças; 3) há grande interesse pelo neoateísmo, com ênfase na produção intelectual de seus principais expoentes, nas associações de ateus e no trabalho de divulgação de materiais na internet (p. 25).

Os dois capítulos seguintes exploram os campos político-ideológicos nos quais o ateísmo foi mais profícuo desde meados do oitocentos até a metade do século XX. Nesse sentido, o Ateísmo no anarquismo brasileiro é investigado ao longo do segundo capítulo, começando por sua vinculação à produção de discursos, representações e práticas libertárias, laicistas e anticlericais. Para tanto, são discutidos os fundamentos do anarquismo e seus pensadores mais significativos, como Pierre-Joseph Proudhon e Mikhail Bakunin, bem como o espaço que dedicam em suas obras à crítica da religião “como tarefa política da luta pela liberdade das massas populares” (p. 45). Nas formas mais radicais, nenhuma conciliação entre a fé religiosa e engajamento político no campo das esquerdas é possível e "a revolução deve [portanto] ser ateia: a experiência histórica e a lógica, a um só tempo, mostram que basta um único senhor no céu para milhares deles na terra” (Bakunin apud p. 46).

À diferença do que ocorria na colônia e no império, em que as críticas à Igreja Católica (religião oficial do Estado) eram tratadas como “blasfêmias e apostasias”, o autor indica o surgimento de um anticlericalismo orgânico, com substrato social bastante significativo, a partir do último quartel do século XIX e nas primeiras décadas da vida republicana (ver como complemento as análises de DI STEFANO, 2010). “Um sentimento que encontrou guarida entre intelectuais” (p. 49) críticos a nossas heranças ibéricas (católicas), mas que se espraiou, sobretudo por meio da imprensa alternativa, para o proletariado nascente e que se organizava em 
sindicatos e associações trabalhistas, nas quais se desenvolveu inclusive uma "verve ateia” e militante. Algo que pode ser compreendido através das discussões sobre religião durante os congressos operários ou por meio dos periódicos editados por esses trabalhadores.

O principal desses jornais (pela duração e abrangência) foi A Lanterna, que circulou, com algumas interrupções, entre 1901 e 1935, com um total de 398 número publicados (p. 63). A periodicidade e o financiamento das atividades desse veículo de imprensa também variaram, assim como as abordagens com relação à religião. De modo geral, pode-se dizer as modalidades de crítica respondiam aos contextos políticos, variando de uma valorização da ciência e da luta pelo Estado laico até uma crítica mais feroz ao "cancro clerical-jesuítico” (p. 72) ou à “questão do ensino religioso nas escolas”, na qual os padres são identificados como "agentes assoldados do fascismo (...) e seus odiosos comparsas” (p. 81).

O Ateísmo no marxismo brasileiro é analisado no terceiro capítulo. De forma semelhante à abordagem conferida ao anarquismo, Ricardo Silva começa por discutir o que é o marxismo, o socialismo e o comunismo e as formas pelas quais o "ateísmo materialista” aparece nos escritos de Karl Marx e Friedrich Engels, bem como do hegeliano de esquerda, Ludwig Feuerbach - nesse caso, como “ateísmo antropológico”. Em síntese, é explanado como em seus vários escritos, mas de modo especial em A ideologia alemã e Sobre a questão judaica, Marx propõe ir além da constatação de Feuerbach de que “o homem faz a religião”, sustentando a necessidade uma crítica profunda da vida material e das relações de trabalho que produzem as condições sociais nas quais surgem as explicações metafísicas e as instituições religiosas. Assim, “a crítica da religião” passa a ser “o pressuposto de todas as críticas: ‘a luta contra a religião é, indiretamente, contra aquele mundo cujo aroma espiritual é a religião”” (p. 98). Nessa perspectiva, não basta a emancipação política burguesa, focada no indivíduo, mas é necessário “emancipar-se da religião de Estado”, empurrando a influência das crenças “do direito público para o direito privado” (Marx apud p. 100).

Na sequência, o autor problematiza as formas pelas quais o marxismo foi recebido no Brasil - política e socialmente filtrado pela influência do leninismo - por meio do Partido Comunista Brasileiro. Daí a importância de considerar as reflexões de Vladimir Lênin sobre a religião “como uma das formas de opressão espiritual” das classes exploradas (p. 110), mas como um assunto secundário na construção da revolução. Talvez por isso o ateísmo nunca tenha constado nas “linhas programáticas do partido”. Da mesma forma, nos congressos do PCB “não 
aparece uma linha sobre o tema” (p. 116). Há nas diretrizes e manifestos produzidos por lideranças partidárias (como Luís Carlos Prestes, por exemplo) apenas referências à defesa da laicidade e das minorias religiosa, com ênfase para a necessária “separação entre Igreja e Estado" (p. 120), mas sem a defesa “do ateísmo materialista como bandeira política” (p. 129). Na parte final do capítulo são apresentadas as “escassas reflexões sobre o ateísmo” (p. 129) nos textos de dois autores marxistas brasileiros: Octávio Brandão e Caio Prado Junior.

No capítulo intitulado Ateísmo brasileiro no início do século XXI são debatidas várias questões: a formação de uma identidade ateísta contemporânea, o peso da ciência no que se convencionou chamar neoateísmo e a importância tanto das associações de ateus quanto da internet nas novas formas de ativismo antirreligioso. De modo comparativo, são mobilizados os números de ateus - no mundo e no Brasil, com o questionamento de que talvez as estatísticas encubram parte dos descrentes, seja pelas dificuldades ainda existentes de declarar-se ateu (em função dos estigmas) ou mesmo da própria formulação das perguntas nos censos demográficos. Por outro lado, Ricardo Silva chama a atenção para o surgimento de um “ateísmo público” (o termo é de Paul Cliteur), nos "moldes dos novos movimentos sociais” ou "movimentos culturais”, com uma pauta fortemente identitária, que convida os ateus a "saírem do armário" - um movimento que na América do Norte tem permitido tanto o surgimento de associações/fundações ateias como a organização de marchas e encontros públicos, para debates. De modo correlato, mas ainda tímido, o mesmo tem acontecido no Brasil, como se pode verificar nos casos da Associação Brasileira de Ateus e Agnósticos (ATEA), a Liga Humanista Secular do Brasil (LiHS) ou da Associação Ateísta do Planalto Central (APCE) (p. 171) ou na multiplicação de “websites, páginas virtuais, blogs e fóruns on-line (...) usados pelos ateus para partilhar preocupações comuns e construir identidades” (p. 170) que gravitam em torno da descrença no sobrenatural.

O autor também apresenta um panorama relativamente amplo das proposições dos intelectuais de maior sucesso internacional do neoateísmo - Sam Harris, Richard Dawkins, Daniel Dennett e Christopher Hitchens (p. 148ss.). Guardadas as peculiaridades de cada um, seria possível identificar alguns traços comuns em seus livros, como a ênfase na razão, no secularismo (com separação total entre religião e política) e na liberdade; a "promoção do cientificismo" (com ênfase no evolucionismo darwinista) e a crítica radical às teocracias e fundamentalismos (identificados com os monoteísmos). Partindo da tipologia elaborada LeDrew, o neoateísmo é tomado, por um lado, como "um subgrupo de um movimento maior de livre-pensadores” (p. 
160), mas que também se subdivide em correntes mais alinhadas à direita política, como é o caso dos “racionalistas libertários” - defensores do livre-mercado (p. 161) ou, mais à esquerda, dos "humanistas seculares” - “engajados na luta pela diferenciação das esferas religiosa (privada) e secular (pública) (...), menos inclinados a atacar as crenças religiosas e mais interessados em questões como educação, desigualdade e sustentabilidade ambiental” (LeDrew apud p. 160).

Por fim, são analisados os estatutos das associações e sua atuação frente à sociedade como um todo e os conteúdos neoateístas veiculados no ciberespaço (o que é denominado de ciber-ateísmo). Os guias teóricos, nesse caso, são Manuel Castells e Pierre Lévy. O primeiro com seus estudos sobre sociedade em rede, o segundo “com a análise sobre a cibercultura” (p. 186). Sobre a atuação da ATEA, da LiHS e da APCE, Ricardo Silva conclui que três eixos norteiam a sua fundação e a atividades que elas têm desenvolvido: 1) defesa de uma identidade ateísta e o combate ao preconceito (o que para Montero e Dullo é um problema, já que toma os ateus como minoria religiosa, inscrevendo-os mais uma vez no campo das crenças); 2) "fomento ao ensino e difusão de sistemas éticos, científicos e filosóficos seculares e 3) engajamento em torno da defesa da laicidade do Estado brasileiro” (p. 172). Já com relação à atuação dos ateus em ambientes virtuais, a análise aponta que ela é uma realidade recente, “que ganhou impulso na última década” (p. 194) e muito variada, merecendo destaque as páginas de "humor antirreligioso”, os canais de vídeo no Youtube e as publicações (em formato digital ou impresso), como a Revista Ateísta, cuja análise ocupa as últimas páginas do livro. Isso se justifica por que nela seriam tematizados o preconceito (p. 200), a identidade e o ativismo ateu (p. 203), a luta pela laicidade do Estado (p. 206), a relação do ateísmo contemporâneo com a ciência (p. 209), com a ética (p. 212) e com o feminismo (215).

Como se pode deduzir dessa breve apresentação, trata-se de um trabalho pioneiro e corajoso, que, sem dúvidas, fomenta o debate, derrocando preconceitos e abrindo caminhos para novos estudos sobre ateísmo no Brasil. Mas, ainda que não comprometam em nada a qualidade do trabalho, algumas questões merecem ser apontadas. Os ensaios, embora guardem uma unidade estilística me parecem muito estanques, dialogando pouco entre si. O que tem relação com a ausência de um ponto de vista mais claro do autor sobre o objeto em foco (pelo menos para os leitores). Creio que, em alguns casos, por provocativa que seja, é a perspectiva do autor, colocada claramente, que cimenta os vários aspectos de uma pesquisa e confere organicidade ao texto. Um caso em que isso me parece exemplar é o de Michel Onfray, em seu Tratado de 
Ateologia (2009). Além disso, há um lapso temporal que incomoda, já que a descrença entre meados do século XX e a emergência do neoateísmo nas duas últimas décadas não é apontada. Autores traduzidos e já estudados no Brasil (cf. Queiroz, Quintiliano, 2012; Valle, 2018), como Charles Taylor, Richard Rorty, André Comte-Sponville, Luc Ferry, Marcel Gauchet e Allain de Botton não são considerados, deixando, assim, de lado, um conjunto de reflexões provenientes da filosofia e das ciências sociais sobre os processos de "saída da religião" que ainda ocupam certa centralidade no debate, sobretudo na Europa, e que poderiam ajudar a compreender o que se passa nessa segunda metade do novecentos.

De qualquer forma é louvável que se tenha dado o primeiro passo e muito bom que se trate de um livro ao mesmo tempo rigoroso em suas análises e de leitura agradável. Um convite para os não-crentes, para os estudiosos do ateísmo e para os que se interessam por entender um pouco mais sobre esse tema.

\section{REFERÊNCIAS BIBLIOGRÁFICAS}

DI STEFANO, Roberto. Ovejas Negras. Historia de los anticlericales argentinos. Buenos Aires: Editorial Sudamerica, 2010.

MONTERO, Paula; DULLO, Eduardo. Ateísmo no Brasil: da invisibilidade à crítica fundamentalista. In: Novos Estudos. São Paulo: CEBRAP, n. 100, nov. de 2014. pp. 57-79.

ONFRAY, Michel. Tratado de Ateologia. Física da metafísica. Trad. de Monica Stahel. São Paulo: Martins Fontes, 2009.

QUEIROZ, José J.; GUEDES, Maria Luiza; QUINTILIANO, Ângela Maria Lucas (org.). Parte III: A onda neoateia no campo da filosofia e da ciência da religião. In: Religião, Modernidade e Pós-Modernidade: interfaces, novos discursos e linguagens. Aparecida: Ideias \& Letras, 2012. pp. 159-219.

VALLE, Edenio (org.). Ateísmo e irreligiosidades. Tendências e comportamentos. São Paulo: Paulinas, 2018. 